\title{
Hypothesis of orogenesis
}

\author{
Leonid Vasyliev ${ }^{1, *}$ \\ ${ }^{1}$ Institute of Geotechnical Mechanics named by N. Poljakov of National Academy of Sciences of \\ Ukraine, 49000, Dnipro, Simferopolska Str., 2a, Ukraine
}

\begin{abstract}
The mechanism of mountain forming is based on the phenomenon of the formation of compressive normal horizontal stresses exceeding gravitational. These stresses are due to contact friction between the layers of rocks. To reveal the mechanism of mountain forming, the vector method of the body equilibrium on the path of maximum effective tangential stresses of a triangular element is used, taking into account the external and internal forces acting on it. It is shown that the total vector of these forces, taking into account internal and contact friction, is directed against the gravitational force and generates mountain forming. A generalization of experimental observations on the elevation of rock structures and anomalous manifestations of rock pressure is given.
\end{abstract}

\section{Introduction}

There are several mountain forming hypotheses in the geological literature [1], according to which the authors of the hypotheses are looking for a force directed against the forces of gravity. In this article we will try to take advantage of their problem statements without engaging in discussion with the authors of the hypotheses and help them to discover the mechanism of the formation of forces leading to mountain forming, such an entertaining natural phenomenon.

Thus, the author [1] writes that gravitational processes are well understood, when the movement occurs down the direction of the action of gravitational forces. In our case, we should get a bottom-up move, i.e. overcome the force of gravity and not only overcome, but also cause the deformation of the rocks. Are there any situations where this is possible? Here, involuntarily, the geologist will come to the incredible idea of the ascent of rocks according to Archimedes law called "the hypothesis of diapirism".

"Sources of forces and movements leading to rock deformations in the folded area, apparently, should be inside it. A group of hypotheses unites one general situation, which boils down to the fact that sedimentary strata in the folded area are deformed under the influence of external concentrated forces, in all cases the problem of rock deformation is presented as one of the standard problems of resistance of materials. [1, p. 50] The negative anomalies of gravity in the mountains are widely known" [1]. Also widely known are the numerous facts related to them, in our opinion, that the horizontal stresses exceed vertical (rock pressure) [2].

\footnotetext{
*Corresponding author: vleonid1937@gmail.com
} 


\section{Experimental results}

In the article [3], from the standpoint of the geomechanics of these massif, we put forward the hypothesis of mountain formation in case of horizontal stresses $\sigma_{x}$ exceeding the gravitational stresses $\sigma_{y}$ in layered rocks. In this paper, an analytical formula is obtained for calculating the horizontal normal stresses of the form

$$
\sigma_{x}=\frac{2\left(k+\mu \sigma_{y}\right)}{\cos \rho}\left(\sin \rho-\sqrt{1-b^{2}}\right)+\sigma_{y}
$$

where $k$ - material resistance to shear; $\sigma_{\mathrm{y}}$ - vertical stress, in particular, $\gamma H$ in massif $(\gamma$ is the specific gravity of the rock, $H$ is the depth of occurrence); $\mu$-coefficient of internal friction of the rock; $\rho=\operatorname{arctg}(\mu)-$ internal friction angle; $b=\frac{f_{k} \sigma_{y}}{k+\mu \sigma_{y}} ; f_{k}$ - coefficient of contact friction of the rock layers.

The formula allows to calculate the horizontal stress $\sigma_{x}<\sigma_{y} ; \sigma_{x}=\sigma_{y}$ and $\sigma_{x}>\sigma_{y}$, arising from contact friction between the layers of rocks.

In this article we will try to reinforce with experimental research the hypothesis of the formation of mountain forming put forward earlier by horizontal normal stresses exceeding the vertical ones generating them. From the transformation of the difference of the second factor of the formula (1), a criterion is obtained for the horizontal stresses to exceed the vertical ones:

$$
b=\left|\frac{f_{k} \sigma_{y}}{k+\mu \sigma_{y}}\right|>\cos \rho
$$

From the condition $b=1$, the theoretically possible maximum value of contact friction is obtained

$$
f_{k}=\frac{k}{\sigma_{y}}+\mu
$$

From the analytical calculation it follows that the horizontal stresses are formed by the tangential stresses from the contact friction between the layers of rocks, i.e. from the resistance to shear on the contact of the formation with lateral rocks. In some works, along with measurements of horizontal stresses, data on the type of rocks between their layers are given. For example, in areas of elevated horizontal stresses of the Khibinsky massif, the properties of rocks are characterized by high strength and adhesion of layers cemented by fine-grained materials [4]. The foregoing suggests that the mechanism of formation of horizontal stresses is directly related to the strength of the contact zones, with their resistance to shear. From the calculation materials provided, it follows that horizontal stresses are generated by vertical forces due to the occurrence of tangential stresses of contact friction from them, and in the crust of gravitational stresses.

Formula (1) is based on the theory of Coulomb strength and is obtained by an analytical method of projecting external forces on the slip platform of an element of a material by the usual methods of the theory of elasticity. But the analytical method has some drawback. To ensure the equilibrium of the material element, it is assumed immediately that the normal stresses in the transverse direction $\sigma_{\mathrm{x}}$ are relative to the current vertical load. In order to clarify the occurrence of stresses $\sigma_{x}$, the article [3] developed a vector method for determining these stresses, which allows to determine the whole range of horizontal 
compressive stresses, including those that exceed the vertical, generating them. However, the vectorial approach to the formation of forces developed by the authors is not sufficiently tested in practice.

Here we use a well-known method in the theory of mechanisms and machines to reveal the mechanism of the formation of horizontal stresses for determining the forces acting on a body moving on an inclined platform [5]. The main position of the method is the condition that the sum of the force vectors applied to the body must be zero. It should be said that, in the theory of elasticity and resistance of materials, the study of the equilibrium of an element of a body comes down to considering the equilibrium of a triangular element, which is an analogue of a moving body along an inclined platform. In this case, the mentally conducted section represents the same inclined platform.

We will use this principle when solving the problem of equilibrium of an element of a material when it is subjected to uniformly distributed external loads. We represent the stresses applied to the faces of the element (triangle) as the corresponding forces, and as the inclined platform we take the line (platform) of the maximum effective Coulomb tangent stresses between the triangular element and the rejected part of the material the angle of friction $\rho$ between the inclined platform and the material element. The force that generates stresses in the transverse direction, relative to the compressive load, performs the functions of a force on an inclined platform.

In the case of the stress state, as well as when considering the body equilibrium on an inclined platform, the movement of a body element, for example, triangular, will be carried out when external loads on the platforms overcome braking forces: friction forces on this platform and material resistance to shear $k_{n}$ and lateral loads attached to the side faces of this body. It is important that the sum of all vectors must be a zero.

Represent the described method in the case of the occurrence in the horizontal direction of compressive normal stresses $\sigma_{x}>\sigma_{y}$.

We formulate the boundary conditions for the deformation of the rock layer during its compression in the presence of outcrop. To simplify the approach, we take normal compressive stresses at the boundary evenly distributed. The boundary conditions affect the numerical values of the normal and tangential active stresses at each point on the contact of the deformable material and, consequently, inside the material. Imagine that the presence of horizontal stresses in the transverse direction is not known in advance. It should be strictly understood that when considering the equilibrium of a triangular element, equilibrium conditions are not considered for stresses (there are no such conditions), but forces acting on the faces [6]. To construct vector diagrams, it is necessary to calculate the parameters of normal and tangential stresses applied to the edges of the triangle, and the angles of inclination of the trajectory of maximum effective tangential stresses (TMETS) with knowledge of physical and mechanical parameters: material resistance to shear, contact and internal friction coefficients; Methods for calculating the parameters of the limiting state of the material with these indicators are set out in the articles [7, 8]. Here we use the results of the calculation.

Consider the anomalous case when $\sigma_{x}>\sigma_{y}$ (Fig. 1). Calculated data: $k_{n}=1.0 ; \mu=1.0$; $f_{k}=1.0 ; \sigma_{y}=61.7 ; \sigma_{x}=101.8 ; \alpha_{a}=121^{\circ} 40^{\prime}$. According to the calculated data we build the total vector of external forces $\bar{N}_{\alpha}$. The shear stress $k_{n}$ and component from the internal friction of Coulomb $\mu \sigma_{\alpha}$ are directed downwards (Fig. 1a).

Let us describe the diagram of the formation of anomalous horizontal normal compressive stresses, exceeding the vertical ones. Based on conditions: $k_{n}=1.0 \mathrm{MPa}, \mu=1.0$; $f_{k}=1.0$ appear that the angle $\alpha=121^{\circ} 40^{\prime}$, strain $\sigma_{y_{i}}=61.7 \mathrm{MPa}$. We build an equilibrium 
triangle with the value of the angle $a b c$, equal to $58^{\circ} 20^{\prime}$. The value of the hypothesis $b c$ is taken equal to one. Then the vertical force is $\bar{N}_{y}=f_{\kappa} \cdot \sigma_{y_{i}} \sin 58^{\circ} 20^{\prime}=20.9 \mathrm{MPa}$

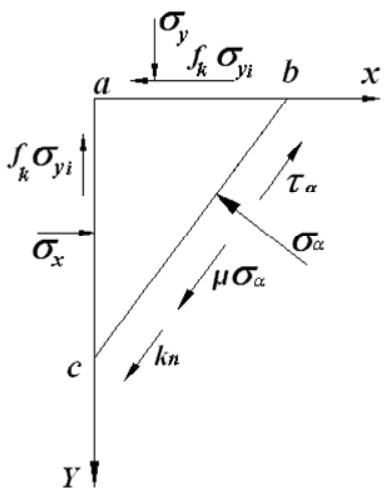

a)

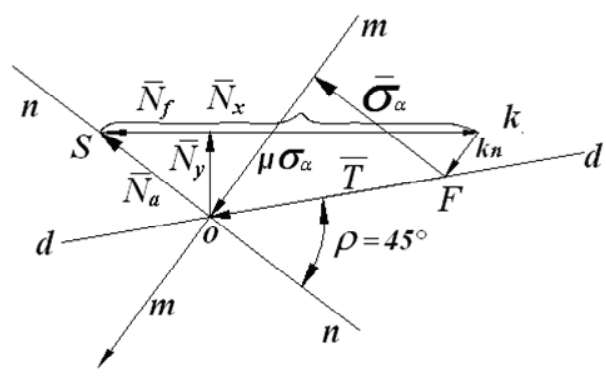

b)

Fig. 1. Vector diagram for determining horizontal normal stresses exceeding the vertical ones: a) equilibrium triangle; $b$ ) - diagram.

The force $\bar{N}_{f}=f_{\kappa} \cdot \sigma_{y_{i}} \cos 58^{\circ} 20^{\prime}=30.2 \mathrm{MPa}$. Through point $\mathrm{O}$ on the hypotenuse $b c$, we draw a line $m m$ parallel to $b c$ on the diagram, and draw a perpendicular line $n n$ to it, relative to which we put the line $d d$, the friction line, by the angle $\rho$. On it we draw the total vector $\bar{T}$ from the addition of vectors $\bar{\sigma}_{\alpha}$ and $\mu \bar{\sigma}_{\alpha}$. The starting point $F$ of the vector $\bar{T}$ is connecting the point $K$ by the line $K F$ parallel to the hypothesis and equal to the resistance of the material to the shift $k_{n}$. So we can add vectors $\bar{N}_{a}, \bar{N}_{x}, \bar{k}_{n}$ and $\bar{T}$, whose sum is equal to zero, which is required by the conditions of the addition of the body's equilibrium forces on an inclined platform. By dividing the value of the vector $N_{x}=86.6 \mathrm{MPa}$ on $\sin 58^{\circ} 20^{\prime}$ we obtain the value of the horizontal voltage of 101.8 MPa, determined by the formula (1) and greater than the vertical strain $\sigma_{y_{i}}=61.7 \mathrm{MPa}$. Due to the excess of the horizontal stresses above the vertical, the directions of the action of the stresses $k_{n}$ and $\mu \sigma_{\alpha}$, are changed, and the triangle $a b c$ rises up, as the resulting vector of vertical forces acts in this direction. This suggests a hypothesis about the nature of mountain forming, because the element in question moves up due to the effect of the resulting load. To balance the resultant vector of the internal load $\bar{R}$, in addition to the vectors $\bar{k}_{n}, \mu \bar{\sigma}_{\alpha}, \bar{\sigma}_{\alpha}$, it is necessary to increment the vector $\bar{N}_{x}$ due to the action of contact tangential stresses. This vector indicates the elongation of the vertical contact parts of the massif due to compressive horizontal normal stresses exceeding the vertical ones, which gives rise to mountain forming. The same conclusion was also noted in the article [9], "highly stressed rock massifs are characterized by elevated speed gradients of modern uplifts of geological structures, anomalous manifestation of rock pressure in underground workings and even in a well". In this book, he gives a number of full-scale photographs confirming the presence of thrust cracks. In the contact zones, longitudinal and transverse deformations change signs to opposite ones due to narrowing of the width and lengthening of the height of the zone due to the material being squeezed out by horizontal stresses exceeding the vertical ones. We argue that the narrowing and elongation in vertical platforms occurs in the contact zones, where the compressive horizontal normal stresses 
exceed those of the vertical. In the middle part of the layer, its usual reduction in height occurs.

In confirmation of the paramount role of horizontal stresses, N.E. Voloshyn [10] gives the actual formation of thrust cracks in underground workings. He further writes that after emissions in the rock mass, cavities are formed, the largest size of which, as a rule, is oriented to the cross of the layering of rocks (up - down). Analysis of the position of the largest cavities of 502 rock emissions that occurred during the construction of the "Petrovska-Hlyboka" mine (now named after Skochynskyi) shows that the vast majority (412) of the largest cavities are located vertically (within $\pm 10^{\circ}$ ). The fall of rocks in the "Petrovska-Hlyboka" mine is $10^{\circ}-15^{\circ}$. Statistical processing of data on the position of the largest sizes of rock emission cavities in the form of a distribution graph is shown in Figure 2. As follows from the figure, the nature of the natural distribution of the largest dimensions of the emission cavities has a sharp direction and leaves no doubt of the absolutely regular vertical (in the cross section of the mine workings) position of the largest size of the cavity of the rock ejection. In the absence of an especially directed stress state of outburst sandstone, it would be necessary to expect a normal distribution of the position of the largest dimensions of the cavities (dashed line in the graph in Fig. 2).

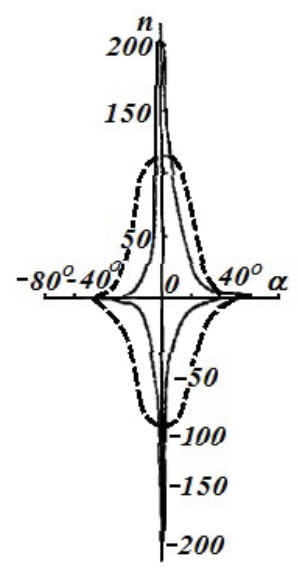

Fig. 2. The distribution of cases of the position of big axes of the cavities of rock emissions in the cross section of excavations.

In this way, we answered geologists to their question, due to which rock is "floating up". Geologists associate it with mountain forming and earthquakes. The author [1] notes that it is still unclear, due to which in this place the energy is locally stored for a future seismic shock, leading to an earthquake. Further he writes that "it is easy to imagine how difficult it is to accomplish such a task, but nevertheless it should be sought to be solved". We physically well represent the answer to the task. Its solvation will be described in the following articles. Here we just say that if a vertical upward force occurs due to high values of horizontal stresses and as a result, elongation deformations occur, then the energy created by them should be discharged when the limit state of the massif is reached and the values of the contact friction coefficient decay according to Saint-Venant as the distance from the contact platform of the tip of the crack during its development. The crack removes some of the material from the load and creates conditions for self-sustaining destruction of the rock massif. The nature of earthquakes in the mountains and rock bursts in underground workings have a common mechanism. 


\section{Conclusion}

1. The mechanism of the formation of mountain forming due to compressive horizontal normal stresses in excess of vertical, due to contact friction between the layers of rocks. The substantiation of the mechanism of mountain formation is given on the basis of the vector method of equilibrium on the trajectory of maximum effective tangential stresses of a triangular element, taking into account the external and internal forces acting on it. It is shown that the total vector of these forces, taking into account internal and contact friction, is directed against the gravitational force and generates mountain forming. A generalization of observations by researchers confirming the formation of mountain forming is given.

2. Mountains are formed by horizontal normal stresses generated by contact friction between the layers of rocks and exceeding the gravitational pressure on the most deformable layers in which they create near-contact deformation zones of elongation against gravity.

\section{References}

1. Sholpo, V.N. (1979). Zemlya raskryvayet svoi tayny

2. Kurlenia, M.V. (1998). Napryazhennoye sostoyaniye porodnykh massivov v verkhnikh sloyakh zemnoy kory. FTPRPI, 3, 3-9

3. Vasyliev, L.M., Vasyliev D.L. (2013). Teoreticheskoye obosnovaniye formirovaniya gorizontal'nykh normal'nykh napryazheniy v massivakh gornykh porod. FTPRPI, 2, 8190

4. Kurlenia, M.V., (1996). Upravleniye gornym davleniyem v tektonicheski napryazhennykh massivakh. KNTS RAN, 1, 162

5. Kozhevnykov S.N. (1973). Teoriya mekhanizmov i mashin. Moscow: Mashinostroyeniye

6. Birger, I.A. (1986). Soprotivleniye materialov. Moskva: Nauka

7. Vasyliev, L.M., Vasyliev D.L. (2013). Analiticheskiy metod postroyeniya diagramm «napryazheniye-deformatsiya» obraztsov gornykh porod pri ikh klinovoy forme razrusheniya. Izvestiya VUZov. Gornyy zhurnal, 7, 80-87

8. Vasyliev, L.M., Vasyliev D.L. (2015). Uchet kontaktnogo treniya $\mathrm{v}$ zadache o razrushenii gornykh porod szhatiyem. FTPRPI, 3, 48-56

9. Neverov, S.A. (2012). Tipizatsiya rudnykh mestorozhdeniy s rostom glubiny po vidu napryazhonnogo sostoyaniya. Part 2. Tektonotipy rudnykh mestorozhdeniy i modeli geosredy. FTPRPI, 3, 25-34

10. Voloshyn, N.E. (2007). Osnovy tektonofizicheskoy teorii vybrosov tverdykh iskopayemykh i porod v shakhtakh. Donetsk: SPD Dmytrenko 